\title{
Mating system, sex ratio, and persistence of females in the gynodioecious shrub Daphne laureola L. (Thymelaeaceae)
}

\author{
M Medrano, C Alonso and CM Herrera \\ Estación Biológica de Doñana, CSIC. Apartado 1056, E-41080, Spain
}

\begin{abstract}
Although in gynodioecious populations male steriles require a fecundity advantage to compensate for their gametic disadvantage, southern Spanish populations of the long-lived shrub Daphne laureola do not show any fecundity advantage over hermaphrodites in terms of seed production and early seedling establishment. By using allozyme markers, we assess the mating system of this species in five populations differing in sex ratio, and infer levels of inbreeding depression over the whole life cycle by comparing the inbreeding coefficients at the seed and adult plant stages. Extremely low outcrossing rates $(0.001<t<0.125)$ were consistently found for hermaphrodites in all populations, whereas, as expected, female progeny were entirely outcrossed. In most
\end{abstract}

populations, offspring were much more inbred than their parents, and heterozygosity of adults was greater than expected from outcrossing rate estimates, with very few selfed progeny appearing to reproduce in the field. The combination of extensive selfing in hermaphrodites and a strong inbreeding depression expressed late in the life cycle (and thus, only estimable by indirect measures based on genetic markers) may explain the persistence and high frequency of $D$. laureola females in southern Spanish populations.

Heredity (2005) 94, 37-43. doi:10.1038/sj.hdy.6800550

Published online 4 August 2004

Keywords: allozymes; female advantage; gynodioecy; inbreeding coefficient; outcrossing rates; sex ratio variation

\section{Introduction}

Gynodioecy is a reproductive system characterized by the coexistence of male steriles ('females' hereafter) and hermaphrodites in plant populations. Despite its relative rarity among flowering plants (5-10\% of species; Charlesworth, 2002), this reproductive system has been the subject of a considerable number of ecological, evolutionary, genetic, and theoretical investigations. Gynodioecy stands out as a particularly interesting study system (Charlesworth, 2002) because of the combination of: (i) theoretical challenges posed by the spread and persistence of female individuals in populations despite their gametic disadvantage relative to hermaphrodites (Lloyd, 1976; Charlesworth and Charlesworth, 1978; Frank, 1989; Bailey et al, 2003); (ii) its significance as an intermediate step in the evolution of dioecy from hermaphroditism (Barrett, 2002); and (iii) the genetic and evolutionary implications of the inherent nucleocytoplasmic genomic conflict when male sterility is determined by cytoplasmic genes (Saumitou-Laprade et al, 1994; Budar et al, 2003).

Irrespective of the mode of inheritance of male sterility, most theoretical models predict that, to spread and persist in populations, female plants must have some consistent fecundity advantage that cancels their gametic

Correspondence: M Medrano, Estación Biológica de Doñana, CSIC. Apartado 1056, E-41080, Spain.

E-mail: monica@ebd.csic.es

Received 14 July 2003; accepted 2 June 2004; published online 4 August 2004 disadvantage (Lloyd, 1976; Gouyon and Couvet, 1987). Although this prediction has received extensive empirical support, occasional exceptions have been reported of species where females lack the fecundity advantage theoretically required for persistence (reviews in Gouyon and Couvet, 1987; Alonso and Herrera, 2001; Shykoff et al, 2003). Such intriguing exceptions provide an opportunity for testing different models for the evolution and maintenance of gynodioecy. On one side, exceptions may stem from imperfect knowledge and, after more rigorous scrutiny of some critical parameters, they could eventually conform to the models they appear to violate. For example, even in the absence of any increase in female fertility, female persistence in populations of selfcompatible species would still be possible with extensive self-fertilization of hermaphrodites combined with a very high level of inbreeding depression over the whole life cycle under natural field conditions (Charlesworth and Charlesworth, 1978). Testing this possibility critically requires detailed information on the species' mating system, particularly the outcrossing rate of hermaphrodites, along with an assessment of inbreeding depression over the whole life cycle. Alternatively, exceptions to the rule of the female fertility advantage may be indicative of other modes of gynodioecy evolution, like those considered by models focusing on population subdivision and associated metapopulation dynamics (McCauley and Taylor, 1997; Pannell, 1997). In gynodioecious species with variable sex ratios, correlations across populations between local sex ratio, on one side, and mating system parameters, population genetic structure, and sex-specific pollination success, on the other, would 
support a role of population subdivision and metapopulation dynamics in female persistence (McCauley and Brock, 1998; McCauley et al, 2000).

Daphne laureola is a gynodioecious shrub whose populations vary widely in the frequency of females (range= 10-60\%). Females and hermaphrodites do not differ in height, number of stems, proportion of stems producing inflorescences, number of inflorescences per flowering stem, number of flowers produced per inflorescence, fruit set, fruit size, and seed size (Alonso and Herrera, 2001). In addition to this absence of female fecundity advantage, there is no evidence of inbreeding depression in seed set, seed size, or seedling emergence under field conditions in this species (Alonso and Herrera, 2001).

This paper has two objectives. First, to test whether the preceding observations actually reflect departures from model requirements for the persistence of females in gynodioecious populations. We will assess the mating system of $D$. laureola hermaphrodites in five southern Spanish populations using allozyme markers, and infer levels of inbreeding depression at the whole life cycle by comparing the inbreeding coefficient at the seed and adult plant stages (Ritland, 1990). Information on the mating system of $D$. laureola presented here is also of interest because the mating system of gynodioecious woody plants has been only rarely investigated (review in Collin and Shykoff, 2003), yet they are expected to differ from that of herbs which have been predominantly studied. Larger floral displays of self-compatible woody perennials like $D$. laureola may increase the frequency of geitonogamous pollinations and lead to higher selfing rates. On the other hand, longer lifespans will result in higher genetic loads and stronger inbreeding depression, which may constrain the evolution of selfing and select for outcrossing mechanisms (Barrett et al, 1996). The second objective of this study is to assess whether differences among $D$. laureola populations in sex ratio, or gender-specific pollination success, are related to variation in mating system. Relatively few studies have so far looked for intraspecific variation in mating system of gynodioecious plants (Collin and Shykoff, 2003).

\section{Materials and methods}

\section{Study species}

D. laureola L. (Thymelaeaceae) is a long-lived, $0.5-1.5 \mathrm{~m}$ tall, evergreen shrub that, in the Mediterranean Region, is generally found in the understorey of coniferous and mixed montane forests. Southern Spanish populations consist of a mixture of hermaphrodite and female individuals, with the local frequency of females ranging between 10 and $60 \%$. Hermaphrodites are fully selfcompatible, but fruit production requires flower visitation by pollinators (Alonso and Herrera, 2001). In our study region (see below), D. laureola flowers during January-April, and the single-seeded black drupes ripen in early June. Plants of both genders produce up to a few thousand long-lasting flowers that are in bloom synchronously throughout the whole flowering period. The yellowish-green tubular flowers are mainly visited by nitidulid beetles, solitary bees, and noctuid moths, mentioned in decreasing order of importance. No information is available on the mechanism of sex determination in D. laureola.

\section{Study sites}

This study was conducted on five disjunct D. laureola populations located in the Natural Park of Sierras de Cazorla-Segura-Las Villas, Jaén province, southeastern Spain. Study locations were Cabeza del Tejo, Cañada del Espino, Coto del Valle, Nava de las Correhuelas, and Roblehondo, hereafter referred to as CT, CE, CV, NC, and $\mathrm{RH}$, respectively. The $\mathrm{RH}$ population was one of the populations considered in an earlier comparative study of fecundity components of female and hermaphrodite plants (Alonso and Herrera, 2001). To enhance the statistical power for detecting mating system correlates of between-population variation in sex ratio, populations were deliberately chosen to encompass nearly the whole range of sex ratios exhibited by the species in the study region. As sex ratio is significantly correlated there with elevation (Alonso and Herrera, 2001), sampling a broad range of sex ratios also resulted in sampling a broad range of elevations. To reduce the possibility of spurious results due to unknown historical or regional trends in population genetic structure, all the study populations chosen were in old, well-preserved mature forests, and were located within a relatively small area (the two most distant populations (CV and $\mathrm{RH}$ ) were only $6.5 \mathrm{~km}$ apart).

\section{Field and laboratory methods}

Sex ratios, floral morphology, and pollen limitation: During the flowering period, the proportion of female and hermaphrodite individuals were determined in the five populations studied. At each site, we scored as many plants as possible for sexual morph (range $=55-145$ plants per site). All plants examined produced exclusively either hermaphrodite or female flowers, and thus were unambiguously classified into one of the two sex morphs. Beyond a threshold size, all D. laureola plants flower every year, so our sex ratio estimates adequately reflect the proportion of sexual morphs in the adult populations sampled.

At the end of the 2002 flowering period (6-29 March), 12 flowers were collected from each of six female and six hermaphrodite plants at each study site $(N=72$ flowers per population and sex) and preserved in 2.5-2.5-95\% formaldehyde-acetic acid-ethyl alcohol (FAA) solution until their dissection and measurement. Styles were softened in $5 \mathrm{M} \mathrm{KOH}$ at $65^{\circ} \mathrm{C}$ for $20 \mathrm{~min}$, rinsed with distilled water, and stained for $20 \mathrm{~min}$ at $65^{\circ} \mathrm{C}$ in decolourized aniline blue. The number of pollen grains on the stigma was counted under a fluorescence microscope. The proportion of stigmas of a given sex morph without pollen grains was used as an index of pollination deficit at the population level. In addition, length of corolla tube was measured on collected hermaphrodite flowers under a dissecting microscope, and mean values were computed for each population. Differences between populations in the mean flower size of hermaphrodites may affect pollination success (through influence on pollinator attractiveness) and mating system parameters. Anther-stigma separation, a parameter known to influence outcrossing rates in other self-compatible plants (Karron et al, 1997; Chang and Rausher, 1998), is directly related to corolla tube length in D. laureola. 
Mating system parameters: To estimate the proportion of selfed versus outcrossed seed, in June 2002 mature fruits (which are always single seeded) were collected from randomly selected plants at each study population. To reduce possible biases in outcrossing estimates due to correlated mating events in nearby flowers, fruits were collected from several branches as widely scattered as possible over each plant and, within each branch, from different infructescences. Collected fruits were kept in sealed plastic vials and brought to the laboratory in a portable cooler. Seeds were prepared for electrophoretic analysis by removing the pulp and seed coat of each fruit, and kept refrigerated until processed. Between 13 and 20 seed families were collected from hermaphrodite plants in each population, and for each seed family electrophoretic genotypes were assayed from seven to 20 seeds (mean $=19.1$ ). Although all the progeny produced by females of gynodioecious plants should be entirely outcrossed, departures from full outcrossing might still occur as a consequence of biparental inbreeding (eg, Maki, 1993). To corroborate that D. laureola females are exclusively or predominantly outcrossed, the mating system of females was also assessed in three populations (CT, CV, and $\mathrm{RH}$ ), where between two and six seed families were collected and 11 and 35 seeds $($ mean $=22.1$ ) were assayed for each seed family.

To genotype adult plants, single flower buds were collected from each of 26, 20, 43, 29, and 20 plants in CT, $\mathrm{CE}, \mathrm{CV}, \mathrm{NC}$, and $\mathrm{RH}$ populations, respectively, in the 2003 or 2004 flowering seasons, brought to the laboratory in a portable cooler, and kept refrigerated until protein extraction $24-48 \mathrm{~h}$ later. Sampled plants included all parent plants from which progeny were collected for determination of outcrossing rates. In addition to these, $2,4,18,9$, and 5 female plants were randomly selected from $\mathrm{CT}, \mathrm{CE}, \mathrm{CV}, \mathrm{NC}$, and $\mathrm{RH}$ populations, in order to match our samples' sex ratios to those of adult plants in the respective populations.

Variation at allozyme loci from seed and flower bud material were assayed with horizontal starch gel electrophoresis. All the extraction, gel, and electrode buffers, and staining procedures were undertaken following the general protocols of Wendel and Weeden (1989). Plant material from each sample was ground in a small volume of a $0.16 \mathrm{M}$ phosphate buffer-PVP solution (slightly modified from Mitton et al, 1979). The crude extract was immediately absorbed onto chromatography paper wicks (Whatman $3 \mathrm{MM}^{\mathrm{TM}}$ ), and kept at $-80^{\circ} \mathrm{C}$ until electrophoresis was performed on $11 \%$ starch gels. From an initial screening of 27 enzymes for electrophoretic variation, band phenotypes could be clearly interpreted for only three variable loci: 6-phosphogluconate-dehydrogenase $(6 p g d)$, phosphoglucomutase $(P g m)$, and malic enzyme $(\mathrm{Me})$. All of them were resolved on the histidine citrate $\mathrm{pH}=6.5$ buffer system, at $45 \mathrm{~mA}$ and $150-170 \mathrm{~V}$. Two alleles were detected for each locus. Genotypes were inferred, based on segregation patterns characteristic of either dimeric or monomeric codominant enzymes. Polymorphic loci conformed to Mendelian expectations for segregation in the analysed progeny arrays.

\section{Statistical analyses}

Differences between populations in corolla tube length were analysed by one-way ANOVA with population as the only fixed factor, provided that corolla length was normally distributed. Differences between populations in the frequency of stigmas without pollen were analysed by Fisher's exact probability tests for female and hermaphrodite flowers separately.

Single- and/or multilocus outcrossing rates $\left(t_{\mathrm{s}}\right.$ and $t_{\mathrm{m}}$ respectively) of hermaphrodite plants were estimated for each population using the method of Ritland and Jain (1981) and the multilocus maximum-likelihood estimation program MLTR 2002 by Ritland (version 2.3, available at http://genetics.forestry.ubc.ca/ritland/programs.html). For the three populations with progenies from female plants $(\mathrm{CV}, \mathrm{RH}$, and $\mathrm{CT})$, separate $t_{\mathrm{s}}$ and $t_{\mathrm{m}}$ values for hermaphrodites and females were obtained in the same program run, treating the two sex morphs as two distinct groups of families sharing the same outcross pollen pool. The Newton-Raphson procedure was used for the iterations. Variances of the estimates were found by bootstrapping 1000 times over all progeny arrays, using families as the unit of resampling. Only one variable locus $(6 P g d)$ was detected in the $C T$ and $C E$ populations, hence only single-locus $\left(t_{\mathrm{s}}\right)$ estimates are available for these sites. In the remaining populations, two variable loci (6Pgd and Pgm in CV; 6Pgd and $\mathrm{Me}$ in $\mathrm{NC}$ and RH) were used to estimate both $t_{\mathrm{s}}$ and $t_{\mathrm{m}}$. The low number of loci utilized in our outcrossing estimates was an unavoidable consequence of the low number of resolvable enzymes showing polymorphism. According to Shaw and Brown (1982), the optimum number of marker loci for estimating outcrossing rates in a plant population depends mainly on the actual level of outcrossing. These authors concluded that, in inbreeders, maximum theoretical efficiency is obtained when only the most variable single locus is used and as many plants as possible are scored for this locus (Shaw and Brown, 1982; see also Ritland and Jain, 1981). As our results will show, D. laureola hermaphrodites have very low outcrossing rates, hence estimates based on one or a few loci may be considered acceptable. As in this study the outcrossing estimates were based on seeds, very earlyacting inbreeding depression (mortality of selfed progeny before fruit maturity due to selective abortion or decreased zygote viability) could contribute to overestimate outcrossing rates. This possibility, however, can be safely ruled out, as a previous study found no significant differences in fruit set between selfed and cross-pollinated, previously emasculated hermaphrodite flowers (Alonso and Herrera, 2001).

For each population, Wright's inbreeding coefficient $\left(\mathrm{F}_{\mathrm{IS}}\right)$ was calculated for the maternal genotypes as $\mathrm{F}_{\mathrm{IS}}=1-H_{\mathrm{o}} / H_{\mathrm{e}}$, where $H_{\mathrm{o}}$ and $H_{\mathrm{e}}$ are, respectively, the observed and expected heterozygosities under random mating. The expected heterozygosity was the unbiased estimator calculated by multiplying the sample expected heterozygosity by the factor $(2 n) /(2 n-1)$. Estimates of $\mathrm{F}_{\mathrm{IS}}$ were combined over loci using the unbiased estimators of Weir and Cockerham (1984) using the GENETIX program version 4.0.4 (Belkhir et al, 2000). To determine if the observed values of the inbreeding coefficient obtained for each population differed significantly from zero, permutation tests were performed $(N=1000$ repetitions) using GENETIX. To determine if observed levels of inbreeding in the adult plants of each population are solely determined by the mating system, the inbreeding coefficient, $\mathrm{F}_{\mathrm{IS}}$, estimated from heterozygosity 
of parent plants was compared to $\mathrm{F}_{\exp }=(1-t) /(1+t)$, the expected level of inbreeding in the population at equilibrium given an outcrossing rate $t$. As female and hermaphrodite plants differed in outcrossing rate, we estimated the outcrossing rate for each population as the mean outcrossing rate of females and hermaphrodites weighted by their respective frequencies in the population: $t=$ (proportion of females $\left.\times t_{\text {females }}\right)+($ proportion of hermaphrodites $\left.\times t_{\text {hermaphrodites }}\right)$. No attempt was made to estimate explicitly inbreeding depression by combining $t$ and $\mathrm{F}_{\mathrm{IS}}$ values using Ritland's (1990) equilibrium estimator, as the underlying model may be invalid when populations are made of a mixture of individuals (females and hermaphrodites) with outcrossing rates so different as those found in this study for D. laureola.

\section{Results}

In addition to their broad differences in sex ratio (range $=21.4-56.1 \%$ females), populations also differed in the mean flower size of hermaphrodites and pollination-deficit levels of the two sexes (Table 1). The mean corolla tube length of hermaphrodite plants, used here as a surrogate for herkogamy, differed significantly among populations $\left(\mathrm{F}_{4,25}=3.93, P=0.01\right)$, tending to decrease at higher elevations. The magnitude of pollination deficit, assessed by the proportion of flowers that did not receive pollen, was significantly different between populations for both females $(P<0.0001)$ and hermaphrodites $(P=0.002)$, although this variation was apparently unrelated to population differences in either altitude or sex ratio (Table 1). The pollination deficit was considerably greater for females (range $=32-85 \%$ of flowers without pollen) than for hermaphrodites (range $=0$ $11 \%$ ) at all populations (Table 1 ). The relative pollination advantage of hermaphrodites over females, measured in either absolute (as the between-sex differential in pollination deficit) or relative (the differential divided by the mean pollination deficit of the two sexes) terms, was apparently unrelated to population differences in elevation or sex ratio.

Extremely low outcrossing rates (both multilocus and singlelocus) were consistently obtained for hermaphrodites in all populations (Table 2). Estimated outcrossing rates departed significantly from zero only in $\mathrm{CT}$, but even at that site as many as $87.5 \%$ of the progeny produced by hermaphrodites were self-fertilized. In the other four populations, estimates indicated that $100 \%$ of hermaphrodite progenies were produced by selfing. Outcrossing rate estimates for females corroborated that progenies of this sex were extensively outcrossed. At the three populations where female progenies were sampled, estimated $t$ values ranged between 0.75 and 1.2 (Table 2), and did not differ significantly from unity at any population.

$\mathrm{F}_{\text {IS }}$ estimates varied widely among populations, ranging between 0.11 (CV and $\mathrm{RH}$ ) and 0.64 (CE) (Figure 1). $\mathrm{F}_{\mathrm{IS}}$ was significantly greater than zero only in $\mathrm{CE}$ and $\mathrm{NC}$ $(P=0.001$ and 0.007 , respectively), thus revealing that significant heterozygote deficit occurred only in these populations. Across populations, an inverse rank correlation was found between $F_{I S}$ and the proportion of females, although it was not statistically significant $\left(r_{\mathrm{s}}=-0.80, P=0.10\right.$, Spearman's correlation coefficient; Figure 1).

In all populations except $\mathrm{CE}$, the inbreeding coefficient of maternal plants $\left(\mathrm{F}_{\mathrm{IS}}\right)$ was considerably lower than the theoretical $F_{\text {exp }}$ equilibrium level expected from population-level outcrossing rates assuming complete outcrossing of females and complete selfing of hermaphrodites

Table 1 Sex ratio, elevation, mean flower size, and sex-specific pollination deficit levels, in the five D. laureola populations studied

\begin{tabular}{|c|c|c|c|c|c|}
\hline \multirow[t]{2}{*}{ Population } & \multirow[t]{2}{*}{ Percent females ${ }^{\mathrm{a}}$} & \multirow[t]{2}{*}{ Elevation ( $m$ a.s.l.) } & \multirow[t]{2}{*}{ Mean hermaphrodite corolla length $(\mathrm{mm})^{\mathrm{b}}$} & \multicolumn{2}{|c|}{ Percent stigmas without pollen ${ }^{c}$} \\
\hline & & & & Females & Hermaphrodites \\
\hline $\mathrm{CV}$ & $56.1(57)$ & 950 & $14.2(0.6)$ & 40.3 & 0 \\
\hline $\mathrm{RH}$ & 34.5 (55) & 1235 & $13.7(0.9)$ & 58.3 & 6.9 \\
\hline NC & 30.1 (133) & 1615 & $12.8(1.3)$ & 84.7 & 11.1 \\
\hline $\mathrm{CT}$ & $28.1(96)$ & 1640 & $12.8(0.4)$ & 73.6 & 11.1 \\
\hline CE & 21.4 (145) & 1575 & $13.7(0.4)$ & 31.9 & 1.4 \\
\hline
\end{tabular}

Populations are listed in decreasing order of female frequency.

aWithin parentheses, number of plants scored for sex morph in each population.

bStandard deviation within parentheses.

'Based on $N=72$ flowers per sex and population ( $=12$ flowers from each of six females and six hermaphrodites sampled per population).

Table 2 Morph-specific multi- and/or single-locus outcrossing rates $\left(t_{\mathrm{m}}\right.$ and $\left.t_{\mathrm{s}}\right)$ in the five populations of D. laureola studied

\begin{tabular}{|c|c|c|c|c|c|c|c|c|}
\hline \multirow[t]{2}{*}{ Population } & \multicolumn{4}{|c|}{ Hermaphrodites } & \multicolumn{4}{|c|}{ Females } \\
\hline & $\mathrm{N}_{\text {families }}$ & $\mathrm{N}_{\text {seeds }}$ & $t_{s}$ & $\mathrm{t}_{m}$ & $\mathrm{~N}_{\text {families }}$ & $\mathrm{N}_{\text {seeds }}$ & $t_{s}$ & $\mathrm{t}_{m}$ \\
\hline $\mathrm{CV}$ & 19 & 358 & $0.024(0.039)$ & $0.024(0.040)$ & 6 & 116 & 0.745 (0.149) & $0.746(0.141)$ \\
\hline RH & 13 & 249 & $0.026(0.016)$ & $0.020(0.012)$ & 2 & 65 & $1.200(0.394)$ & $1.168(0.387)$ \\
\hline $\mathrm{NC}$ & 20 & 400 & $0.001(0.142)$ & $0.001(0.142)$ & - & - & - & - \\
\hline CT & 20 & 372 & $0.125(0.061)$ & - ${ }^{a}$ & 4 & 84 & $0.972(0.149)$ & 一 $^{\mathrm{a}}$ \\
\hline CE & 16 & 299 & $0.026(0.021)$ & —a $^{a}$ & - & - & - & - \\
\hline
\end{tabular}

Standard deviations of estimates within parentheses.

anly one variable locus detected. 


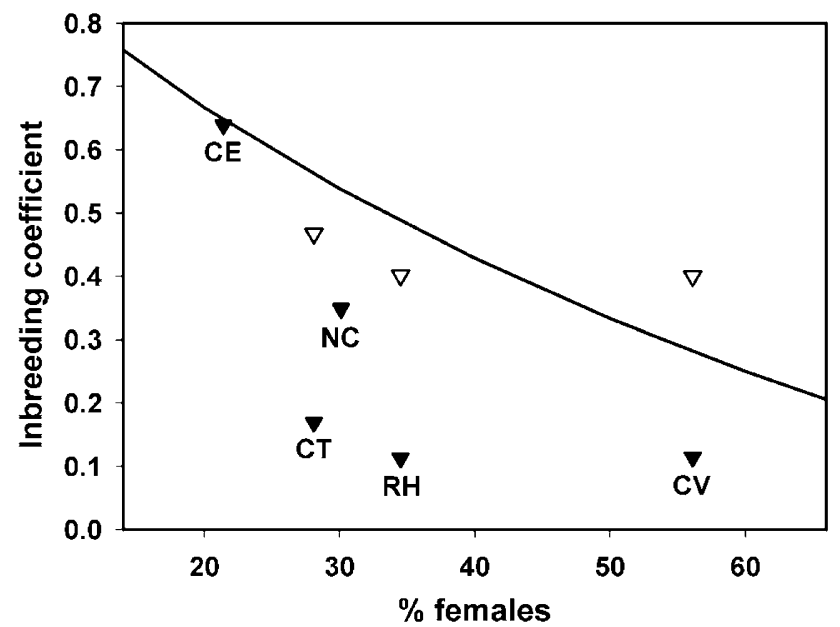

Figure 1 Observed ( $\mathrm{F}_{\mathrm{IS}}$, filled triangles) and expected ( $\mathrm{F}_{\exp }$ continuous line and open triangles) values of the inbreeding coefficient of maternal plants, plotted in relation to the frequency of females in populations. Symbols beside filled triangles identify populations. The curve represents the theoretically expected level of inbreeding in the population at equilibrium, computed as $\mathrm{F}_{\exp }=(1-t) /(1+t)$, where $t$ is the population-level outcrossing rate obtained as a weighted mean of the female and hermaphrodite outcrossing rates. The curve was obtained assuming that the progeny produced by females is completely outcrossed $\left(t_{\text {females }}=1\right)$ 1 ) and the progeny produced by hermaphrodites is completely selfed $\left(t_{\text {hermaphrodites }}=0\right)$, a realistic scenario in D. laureola as shown by this study. Open triangles represent the $\mathrm{F}_{\exp }$ values for $\mathrm{CT}, \mathrm{RH}$, and $\mathrm{CV}$ computed using the actual female and hermaphrodite outcrossing rates estimated at these populations (Table 2).

(Figure 1). $\mathrm{F}_{\text {IS }}$ was also inferior to the empirical estimates of $\mathrm{F}_{\text {exp }}$ in the three populations with female outcrossing rate estimates. Only in $\mathrm{CE}$, the population where the sex ratio was most biased towards hermaphrodites, was the $\mathrm{F}_{\mathrm{IS}}$ of maternal plants roughly similar to $\mathrm{F}_{\text {exp. }}$. Taken together, these results thus suggest that, in most populations, offspring are much more inbred than their parents; heterozygosity of adult plants is greater than that expected from outcrossing rate estimates alone; and few selfed progeny survive to reproduction in the field.

\section{Discussion}

Using allozyme markers, this study has shown that in gynodioecious $D$. laureola virtually all the progeny produced by hermaphrodite plants resulted from selfing whereas, as expected, the progeny of female plants resulted from outcrossing. This pattern was consistent across all populations studied, despite significant differences among populations in the morphology of hermaphrodite flowers, sex ratio, and level of pollination deficit. Our results for females are similar to those reported in earlier studies on other gynodioecious plants, most of which have generally found female outcrossing rates equal or near to unity (review in Collin and Shykoff, 2003). In comparison to other gynodioecious plants, D. laureola stands out with regard to the outcrossing rate of hermaphrodites. We are not aware of any other investigation reporting virtually complete selfing $\left(t_{\mathrm{m}}\right.$ not significantly differing from zero) of hermaphrodites occurring consistently across different populations (references in Collin and Shykoff, 2003; but see Maki, 1993 for some populations of Chionographis japonica). Interpopulation variation in outcrossing rate has been reported in virtually all mixed mating species in which more than three populations have been studied (Sun and Ganders, 1988; Collin and Shykoff, 2003); thus, the extensive selfing of $D$. laureola hermaphrodites is particularly worth noting because it occurs consistently in all populations, and irrespective of variation in several parameters (eg, corolla tube length) that were judged $a$ priori as potentially influential on the mating system. Spontaneous self-pollination is quite infrequent in $D$. laureola hermaphrodites (Alonso and Herrera, 2001), hence it may tentatively be suggested that it is the species' unspecialized pollination system coupled with the large number of long-lasting flowers simultaneously open on individual plants, which accounts for the complete selfing observed at all populations. Adults of the pollen beetle, Meligethes elongatus Rosenhauer, the main pollinator of $D$. laureola in the study region, frequently move between flowers and inflorescences of the same shrub while feeding on pollen and searching for mates, which will generally lead to extensive geitonogamous pollinations in hermaphrodites. It must be noted, however, that D. laureola is a long-lived plant, and hence annual variation in mating system parameters derived from variation in the abundance or foraging behaviour of their pollinating agents cannot be ruled out.

Populations of $D$. laureola considered in this study encompassed nearly the whole range of female frequencies occurring in the study region, yet the outcrossing rate of hermaphrodites remained consistently indistinguishable from zero regardless of population differences in sex ratio. This result contrasts with previous investigations reporting an inverse relationship between female frequency and outcrossing rate of hermaphrodites (Sun and Ganders, 1988; Van Treuren et al, 1993). The decoupling between female frequency and outcrossing rate of hermaphrodites across populations of D. laureola could be explained by the combination of large synchronous floral displays with the limited movements of their main pollinators, resulting in high levels of geitonogamous self-pollination in hermaphrodites irrespective of the percentage of females in the population. Furthermore, these results suggest that, in the study region, $D$. laureola does not conform to predictions derived from models of gynodioecy evolution proposed by McCauley and Taylor (1997) based on concurrent frequencydependent selection and metapopulation dynamics. Nevertheless, this interpretation should be taken with caution, as it is not known the extent to which the main assumptions underlying such models (random mating, high population turnover) hold true in the case of $D$. laureola.

In D. laureola we have also found that heterozygote deficit declined across populations with increasing female frequency, although this relationship was not statistically significant, possibly because of reduced statistical power due to the small number of populations included in the study. Nevertheless, observed $F_{\text {IS }}$ values were much smaller than $F_{\exp }$ at four out of five populations, thus revealing that the frequency of homozygotes in the adult population was much smaller than would be predicted from mating system parameters alone. In the absence of formal computations of inbreed- 
ing depression estimates using Ritland (1990) equilibrium method, this result indicates that few selfed progeny eventually establish in the adult population, and suggests that strong inbreeding depression over the whole life cycle eliminates most selfed progenies before they enter the adult reproductive stage. Keeping in mind the limitations inherent to inferences about inbreeding depression levels based on genetic markers (Kohn and Biardi, 1995; Dorken et al, 2002, and references therein), this method is possibly the only applicable to obtain whole life cycle estimates for long-lived plants like $D$. laureola, where direct measurements of inbreeding depression beyond the earlier stages in the life cycles are impractical. Inbreeding depression levels in these earlier stages are often smaller (eg, Sakai et al, 1997) and, in fact, earlier investigations on D. laureola failed to demonstrate any measurable inbreeding depression effect on fruit set, fruit and seed size, seed germination, and early seedling survival (Alonso and Herrera, 2001; C Alonso, unpublished data). These earlier results negated any fecundity advantage of females over hermaphrodites and, as noted in the Introduction, rendered $D$. laureola a possible exception to the female advantage rule required for the stability of gynodioecy according to theoretical models (Lloyd, 1976; Gouyon and Couvet, 1987).

Results of this study indicate that extensive selfing of D. laureola hermaphrodites in combination with strong inbreeding depression over the whole life cycle will predictably result in a considerable, albeit cryptically expressed reproductive advantage of females over hermaphrodites, as predicted by theoretical models for the stable persistence of females in gynodioecious populations. Although females do not exhibit any fecundity advantage indicative of resource compensation (Alonso and Herrera, 2001), they do with regard to the greater quality of the progeny. According to the 'outcrossing-advantage hypothesis', inbreeding depression could reduce the inherent gametic advantage of hermaphrodites in self-compatible gynodioecious plants whenever selfing rate differs from zero. Furthermore, stable persistence of male-sterility factors in the absence of a fecundity advantage would require a combination of very high levels of inbreeding depression and extensive hermaphrodite selfing (Lloyd, 1975; Charlesworth and Charlesworth, 1978). Simultaneous occurrence of extensive selfing of hermaphrodites and high inbreeding depression has also been reported for other gynodioecious plants like Plantago coronopus (Wolff et al, 1988), Cucurbita foetidissima (Kohn, 1988; Kohn and Biardi, 1995), Bidens sandvicensis (Schultz and Ganders, 1996), and Schiedea adamantis (Sakai et al, 1997). Results of this study are fully consistent with these expectations and indicate that explanations for the persistence of females in gynodioecious D. laureola need not be sought beyond the conventional theoretical framework.

While the results of this study provide evidence explaining the stable persistence of females in D. laureola, they raise questions about the persistence of hermaphrodites. If few of the entirely selfed progeny of hermaphrodites reach adulthood under field conditions, then the breeding system of D. laureola in our study region would exemplify a case of functional dioecy where hermaphrodites actually behave as males, since they transmit genes to the next generation only via the pollen siring the seeds produced by females. D. laureola would thus exemplify the next-to-last stage in the transition from hermaphroditism to dioecy via gynodioecy (Barrett, 2002). It remains to be explained, however, why the transition has been not completed, given the nutritional and energetic costs incurred by hermaphrodites in developing and ripening fruits that will eventually contribute no progeny, and the gametic losses derived from pollen discounting associated with extensive self-fertilization. Hermaphrodite flowers without female parts, or hermaphrodite plants consistently failing to produce fruits, have been not found so far in any southern Spanish population. Furthermore, although gynodioecy is not uncommon in the genus Daphne, none of its approximately 100 species seems to have evolved to dioecy (Brickell and Mathew, 1981). The absence of 'female sterile' individuals in gynodioecious species may be due to ecological conditions causing an early saturation of the pollen fitness gain curve, developmental constraints precluding or limiting the evolution of female sterility without consequent deleterious pleiotropic effects, or strong developmental integration of floral traits (Schultz, 1994; Ashman, 1999). Further studies are needed on $D$. laureola to elucidate the possible influence of these factors in the persistence of hermaphrodites in this gynodioecious species.

\section{Acknowledgements}

We thank M García, J Muñoz, R Requerey, and the staff of Laboratorio de Ecología Molecular, Estación Biológica de Doñana, for laboratory assistance; RG Albaladejo, A Aparicio, SCH Barrett, and WW Cole for essential advice and encouragement; K Ritland for advice on application of MLTR program to our data; SCH Barrett, P Mutikainen, and three anonymous reviewers for useful comments on the manuscript; and the Consejería de Medio Ambiente, Junta de Andalucía, for facilities in Cazorla. MM was supported by a postdoctoral grant from the Ministerio de Educación y Cultura (EX2001 35313421) and a postdoctoral contract from the Consejo Superior de Investigaciones Científicas (I3P Program), financed by the Fondo Social Europeo, and CA by a contract from the Ramón y Cajal program of the Ministerio de Ciencia y Tecnología. This work was partly supported by Grant BOS2000-1122-C03-01 from Ministerio de Ciencia y Tecnología.

\section{References}

Alonso C, Herrera CM (2001). Neither vegetative nor reproductive advantages account for high frequency of malesteriles in southern Spanish gynodioecious Daphne laureola. Am J Bot 88: 1016-1024.

Ashman TL (1999). Quantitative genetics of floral traits in a gynodioecious wild strawberry Fragaria virginiana: implications for the independent evolution of female and hermaphrodite floral phenotypes. Heredity 83: 733-741.

Bailey MF, Delph LF, Lively CM (2003). Modeling gynodioecy: novel scenarios for maintaining polymorphism. Am Nat 161: 762-776.

Barrett SCH (2002). The evolution of plant sexual diversity. Nat Rev Gen 3: 274-284.

Barrett SCH, Harder LD, Worley AC (1996). The comparative biology of pollination and mating in flowering plants. Philos Trans R Soc Lond Ser B 351: 1271-1280. 
Belkhir K, Borsa P, Chikhi L, Raufaste N, Bonhomme F (2000). GENETIX 4.0, logiciel sous Windows pour la génétique des populations, Laboratoire Génome, Populations, Interactions, Université de Montpellier II, Montpellier: France.

Brickell CD, Mathew B (1981). Daphne: The Genus in the Wild and in Cultivation, Alpine Garden Society: Surrey.

Budar F, Touzet P, de Paepe R (2003). The nucleo-mitochondrial conflict in cytoplasmic male sterilities revisited. Genetica 117: 3-16.

Chang S-M, Rausher MD (1998). Frequency dependent pollen discounting contributes to maintenance of a mixed mating system in the common morning glory Ipomoea purpurea. Am Nat 152: 671-683.

Charlesworth D (2002). What maintains male-sterility factors in plant populations? Heredity 89: 408-409.

Charlesworth D, Charlesworth B (1978). A model for the evolution of dioecy and gynodioecy. Am Nat 112: 975-997.

Collin CL, Shykoff JA (2003). Outcrossing rates in the gynomonoecious-gynodioecious species Dianthus sylvestris (Caryophyllaceae). Am J Bot 90: 579-585.

Dorken ME, Friedman J, Barrett SCH (2002). The evolution of monoecy and dioecy in Sagitaria latifolia (Alismataceae). Evolution 56: 31-41.

Frank SA (1989). The evolutionary dynamics of cytoplasmic male sterility. Am Nat 133: 345-376.

Gouyon PH, Couvet D (1987). A conflict between the two sexes, females and hermaphrodites. In: Stearns SC (ed) The Evolution of Sex and its Consequences, Birkhäuser: Basel. pp 245-261.

Karron JD, Jackson RT, Thumser NN, Schlicht SL (1997). Outcrossing rates of individual Mimulus ringens genets are correlated with anther-stigma separation. Heredity 79: 365-370.

Kohn JR (1988). Why be female? Nature 335: 431-433.

Kohn JR, Biardi JE (1995). Outcrossing rates and inferred levels of inbreeding depression in gynodioecious Cucurbita foetidissima (Cucurbitaceae). Heredity 75: 77-83.

Lloyd DG (1975). The maintenance of gynodioecy and androdioecy in angiosperms. Genetica 45: 325-339.

Lloyd DG (1976). The transmission of genes via pollen and ovules in gynodioecious angiosperms. Theor Popul Biol 9: 299-316.

Maki M (1993). Outcrossing and fecundity advantage of females in gynodioecious Chionographis japonica var. kurohimensis (Liliaceae). Am J Bot 80: 629-634.

McCauley DE, Taylor DR (1997). Local population structure and sex ratio: evolution in gynodioecious plants. Am Nat 150: 406-419.
McCauley DE, Brock MT (1998). Frequency-dependent fitness in Silene vulgaris, a gynodioecious plant. Evolution 52: 30-36.

McCauley DE, Olson MS, Emery SN, Taylor DR (2000). Population structure influences sex ratio evolution in a gynodioecious plant. Am Nat 155: 814-819.

Mitton JB, Linhart YB, Sturgeon KB, Hamrick JL (1979). Allozyme polymorphisms detected in mature needle tissue of ponderosa pine. J Hered 70: 86-89.

Pannell J (1997). The maintenance of gynodioecy and androdioecy in a metapopulation. Evolution 51: 10-20.

Ritland K (1990). Inferences about inbreeding depression based on changes of the inbreeding coefficient. Evolution 44: 1230-1241.

Ritland K, Jain SK (1981). A model for the estimation of outcrossing rate and gene frequencies using $n$ independent loci. Heredity 47: 35-52.

Sakai AK, Weller SG, Chen M-L, Chou S-Y, Tasanont C (1997). Evolution of gynodioecy and maintenance of females: the role of inbreeding depression, outcrossing rates, and resource allocation in Schiedea adamantis (Caryophyllaceae). Evolution 51: 724-736.

Saumitou-Laprade P, Cuguen J, Vernet P (1994). Cytoplasmic male sterility in plants: molecular evidence and the nucleocytoplasmic conflict. Trends Ecol Evol 9: 431-435.

Schultz ST (1994). Nucleo-cytoplasmic male sterility and alternative routes to dioecy. Evolution 48: 1933-1945.

Schultz ST, Ganders FR (1996). Evolution of unisexuality in the Hawaiian Flora: a test of microevolutionary theory. Evolution 50: 842-855.

Shaw DV, Brown AHD (1982). Optimum number of marker loci for estimating outcrossing in plant populations. Theor Appl Genet 61: 321-325.

Shykoff JA, Kolokotronis SO, Collin CL, López-Villavicencio M (2003). Effects of male sterility on reproductive traits in gynodioecious plants: a meta-analysis. Oecologia 135: 1-9.

Sun M, Ganders FR (1988). Mixed mating systems in Hawaiian Bidens (Asteraceae). Evolution 42: 516-527.

Van Treuren R, Bijlsma R, Ouborg NJ, Van Delden W (1993). The effects of population size and plant density on outcrossing rates in locally endangered Salvia pratensis. Evolution 47: 1094-1104.

Weir BS, Cockerham CC (1984). Estimating F-statistics for the analysis of population structure. Evolution 38: 1358-1370.

Wendel JF, Weeden NF (1989). Visualization and interpretation of plant isozymes. In: Soltis DE, Soltis PS (eds) Isozymes in Plant Biology, Dioscorides: Portland, OR. pp 5-45.

Wolff K, Friso B, Van Damme JMM (1988). Outcrossing rates and male sterility in natural populations of Plantago coronopus. Theor Appl Genet 76: 190-196. 